\title{
Numerical Modelling of Mining Near and Beneath Tailings Dam
}

\author{
M.A. Coulthard M.A. Coulthard and Associates Pty Ltd, Australia \\ G.E. Holt G.E. Holt and Associates Pty Ltd, Australia
}

\begin{abstract}
Two coal mining companies proposed to undertake, respectively, longwall mining beneath an existing tailings dam, and open cut mining adjacent to it. $3 D$ numerical stress analyses, using program FLAC ${ }^{3 D}$, were performed to examine this system, as one component of meeting regulatory requirements. Rock cohesions and tensile strengths from earlier $2 D$ modelling had to be reduced by a factor of five to produce modelled surface subsidence comparable with that observed over previous longwall panels. Those properties were then used in the final models, resulting in predicted factors of safety not less than 1.80 for the open cut walls and for the tailings dam. The longwall panels have since been mined, and the open cut is close to completion, without incident.
\end{abstract}

\section{Introduction}

In the Hunter Valley Coalfield of New South Wales, United Collieries Pty Ltd conducts coal extraction by the longwall method beneath open cut mining operations of Wambo Coal Pty Ltd. The open cut operations include major active and inactive tailings dams, auger-mining of highwalls and open cut mining of three coal seams; the Redbank, Wambo and Whynot seams. The underground longwall operation extracts coal from the Woodlands Hill seam, $100 \mathrm{~m}$ beneath the Whynot seam, the lowest seam mined by open cut methods.

One tailings dam is in the final void of the Northeast open cut. The open cut was $1.5 \mathrm{~km}$ long and in the 1990s a wall was built along part of the crest and across the final void near its eastern end, to develop a fine coal tailings repository $1.2 \mathrm{~km}$ long and up to $250 \mathrm{~m}$ wide (see Figure 1). The end wall developed seepage problems in 2000. Following this the tailings dam was prescribed under the Dams Safety Act of New South Wales. This forced rigorous regulatory demands on mining near, and underneath the tailings dam.

The two mining companies were required to prove to the satisfaction of the New South Wales Dams Safety Committee that longwall extraction beneath, and open cut mining around the Northeast cut tailings dam would not affect its integrity. The complex interaction of surface and underground mining was modelled, using the program FLAC $^{3 \mathrm{D}}$ (Itasca, 2006), to predict the nature and significance of ground movements.

The general area had been subjected to detailed geotechnical investigations for earlier proposals to highwall mine, then to auger mine the surrounding highwalls. Those investigations included geotechnical logging and testing of core retrieved from a number of boreholes, and mathematical modelling of auger mining into the highwalls surrounding the tailings dam using the 2D companion program FLAC (Itasca, 2005). The subsequent successful auger mining of the highwalls gave reassurance that the geotechnical information used in the $2 \mathrm{D}$ modelling could provide a viable starting point for a $3 \mathrm{D}$ examination of the proposed combined open cut and underground mining.

In addition to the geotechnical work previously undertaken, extensive surface subsidence and movement monitoring had been undertaken over each longwall panel extracted by United Collieries Pty Ltd as part of other statutory requirements. The subsidence and movement data provided a means of calibrating the modelling process. This was particularly important as, until this exercise, accurate modelling of mine subsidence had proved elusive. 


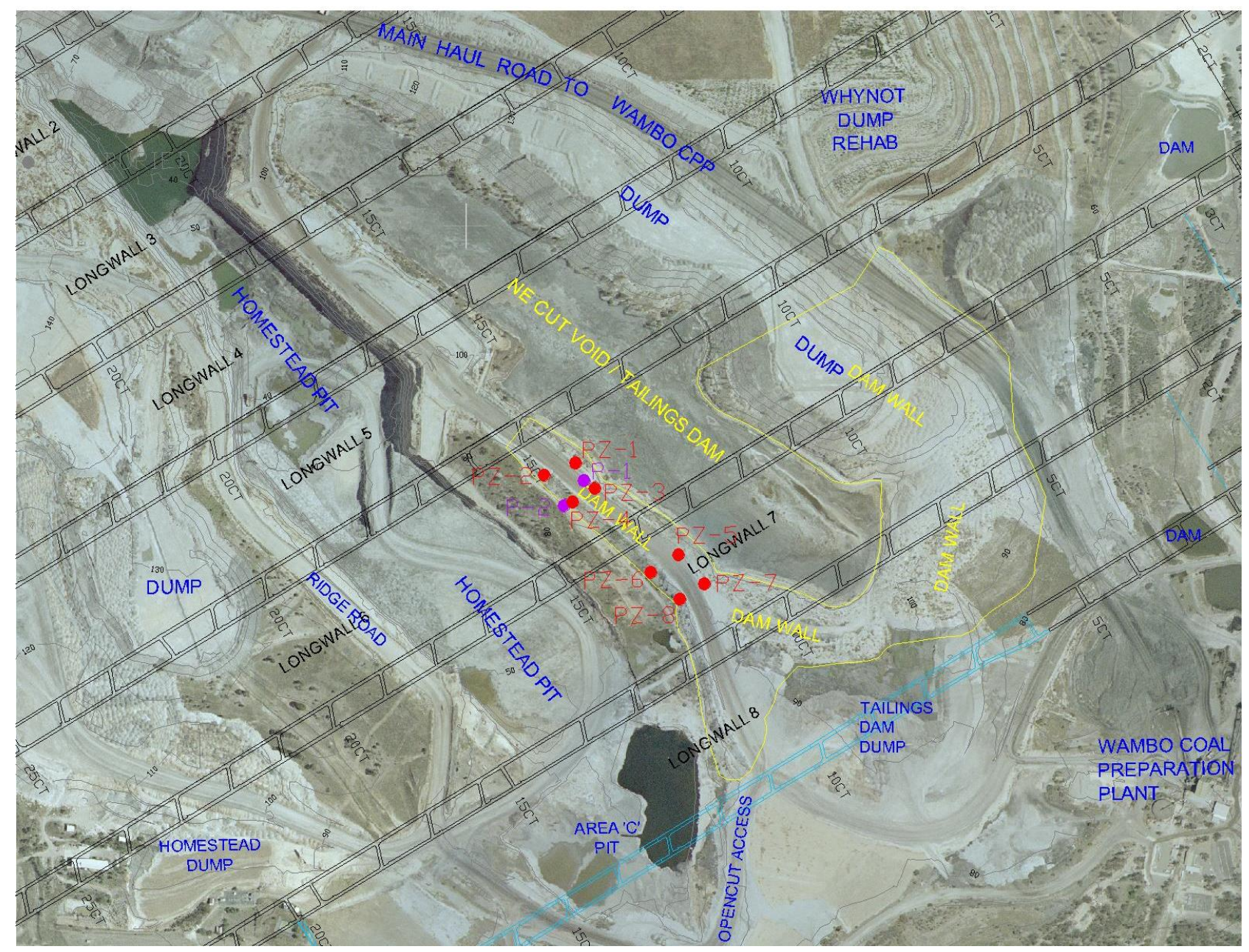

Figure 1 Location map of Northeast cut tailings dam, showing longwall extraction layout beneath, and Homestead open cut below the embankment

\section{Geological and geotechnical data}

A geological model for the tailings dam area was prepared, using information from seven boreholes that surrounded the tailings dam (United Collieries and Wambo Coal, 2006).

The Singleton coal measures are typically a combination of interbedded arenites and lutites, or mixtures of these between the numerous coal seams. Lutites are variously logged as shale, mudstone, siltstone, claystone and mixtures of these. As most lutites in the Singleton coal measures are fissile to some degree they can all be classified as shale for modelling at the scale required for the mathematical model. The rock strata thus could be simplified to four lithologies: sandstone, coal, shale and an interbedded mix of sandstone and shale.

In developing the model for the $\mathrm{FLAC}^{3 \mathrm{D}}$ analyses the limitations of mathematical simulation of caving rock strata needed to be acknowledged, and an appropriate level of geological detail provided that was consistent with those limitations yet realistically simulated actual ground conditions. Some of the thinner strata had to be omitted from the numerical models because the FLAC ${ }^{3 \mathrm{D}}$ finite difference grid could not be made fine enough without also forcing computer run times to become unacceptably large. The geological strata that were built into the final models are listed in Table 1 . The strata had an overall dip of $2.5^{\circ}$ (see Figure 2 ). 
Table 1 Geological model used in FLAC ${ }^{3 \mathrm{D}}$ analyses of undermining of dam

\begin{tabular}{|c|c|c|}
\hline Rock Unit & RL of Top of Layer (m) & Layers of Zones in Unit \\
\hline Sandstone/shale & 0 & 2 \\
\hline Redbank coal seam & -10 & 1 \\
\hline Sandstone/shale & -15 & 2 \\
\hline Sandstone & -25 & 3 \\
\hline Wambo coal seam & -40 & 1 \\
\hline Sandstone/shale & -45 & 2 \\
\hline Shale & -55 & 1 \\
\hline Whynot coal seam & -60 & 2 \\
\hline Sandstone/shale & -69 & 4 \\
\hline Shale & -85 & 2 \\
\hline Sandstone/shale & -95 & 2 \\
\hline Sandstone & -105 & 3 \\
\hline Sandstone/shale & -120 & 2 \\
\hline Sandstone & -130 & 1 \\
\hline Shale & -135 & 2 \\
\hline Sandstone/shale & -145 & 3 \\
\hline Coal & -160 & 1 \\
\hline Sandstone & -165 & 10 \\
\hline Shale & -195 & 1 \\
\hline Woodlands Hill coal seam & -197 & 2 \\
\hline Sandstone/shale & -200.5 & 3 \\
\hline Sandstone & -205.5 & 2 \\
\hline Coal & -210 & 1 \\
\hline Shale & -215 & 1 \\
\hline Sandstone & -220 & 8 \\
\hline
\end{tabular}

Properties were provided for the various rock units, for an assumed Mohr-Coulomb elastic-plastic constitutive model (United Collieries and Wambo Coal, 2006) see Table 2. Considerable laboratory testing of rock samples from the Wambo Coal Mining lease had occurred over a 25 year time frame, so there was a large volume of test data. In addition, there had been several phases of mathematical modelling for longwall extraction, and also mathematical modelling for auger mining adjacent to the tailings dam (Holt, 2003). Auger mining was successfully concluded, and this provided some calibration of the rock properties recommended for the FLAC ${ }^{3 \mathrm{D}}$ exercise. The rock properties also compared favourably with those used in FLAC modelling in the Hunter Valley Coalfield for some 20 years.

During the course of testing of early models for this project, it was decided that interfaces would be placed at the base of the Whynot and Wambo coal seams, to allow for slip and separation there if the response of the rock mass required it. Also, interfaces had to be set up on the floor of each section of longwall, so that the collapsing roof would register contact with the floor and begin to carry load. Finally, some dummy (high strength) interfaces were needed to connect sections of the finite difference grid, where zones and gridpoints on either side did not match; this is a standard procedure in FLAC ${ }^{3 \mathrm{D}}$ modelling. The properties used for those 
various interfaces are given in Table 3. The friction angle for the floor of coal seams was based on back analysis of failure on coal floors, whilst that for the longwall panels was the minimum of those for the rock units on either side of the Woodlands Hill seam (Table 2).

The initial values for in situ stresses for all models were based upon an average density of $2500 \mathrm{~kg} / \mathrm{m}^{3}$ and $\mathrm{K}_{0}=1.0$ (latter value was estimated because no data were available). Groundwater pressures were not included in any of these models.

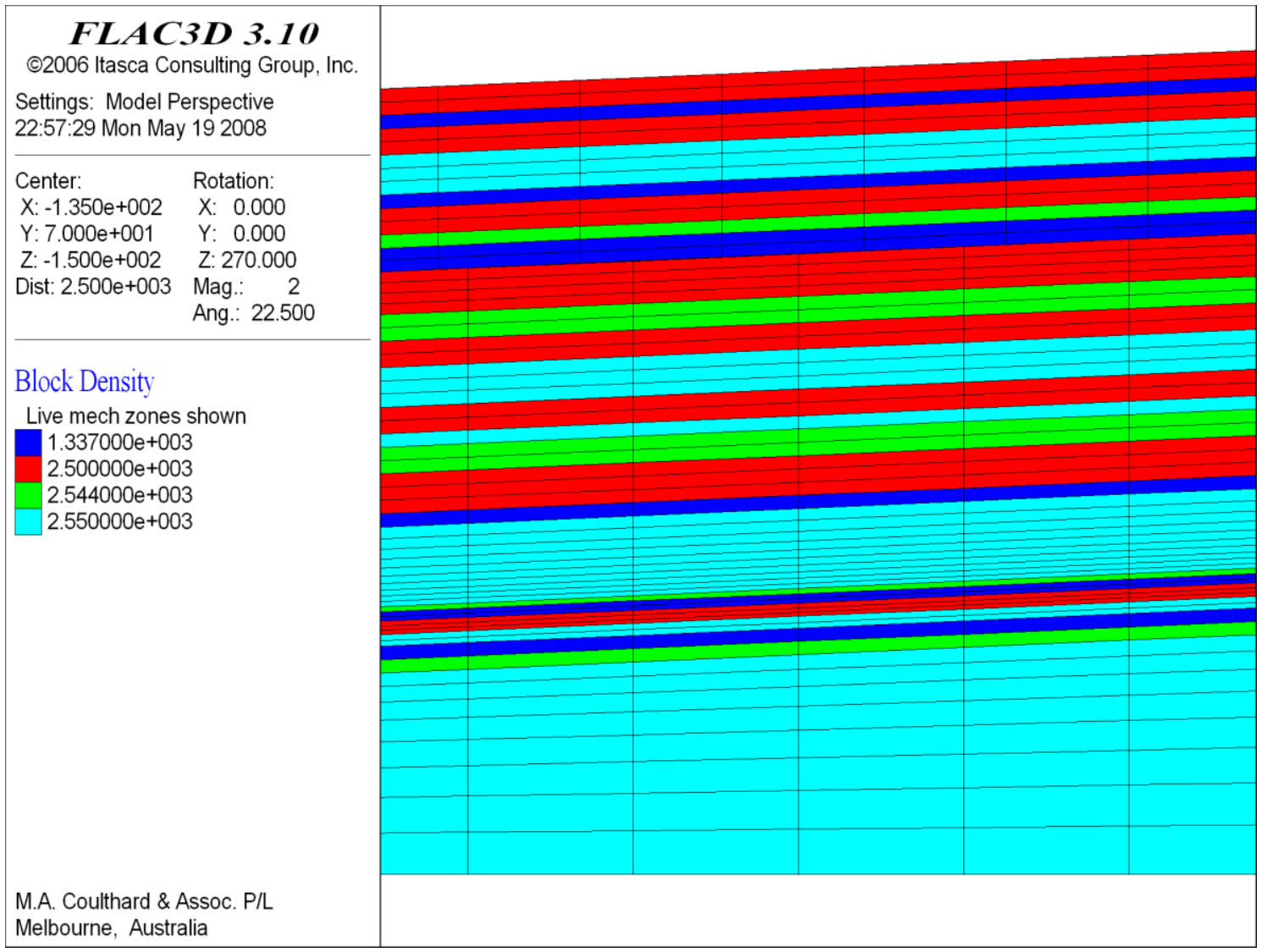

Figure 2 Rock strata included in numerical models, shown by density (as in Table 2)

Table 2 Initial properties for rock units

\begin{tabular}{lccccccc}
\hline Rock Unit & $\begin{array}{c}\text { Density } \\
\left(\mathrm{kg} / \mathrm{m}^{3}\right)\end{array}$ & $\begin{array}{c}\text { Bulk } \\
\text { Modulus } \\
(\mathrm{GPa})\end{array}$ & $\begin{array}{c}\text { Shear } \\
\text { Modulus } \\
(\mathrm{GPa})\end{array}$ & $\begin{array}{c}\text { Friction } \\
\text { Angle } \\
(\mathrm{deg})\end{array}$ & $\begin{array}{c}\text { Cohesion } \\
(\mathrm{kPa})\end{array}$ & $\begin{array}{c}\text { Tensile } \\
\text { Strength } \\
(\mathrm{kPa})\end{array}$ & $\begin{array}{c}\text { Dilation } \\
\text { Angle } \\
(\mathrm{deg})\end{array}$ \\
\hline Sandstone/shale & 2500 & 2.57 & 1.17 & 30 & 2000 & 1600 & 0 \\
Wambo and Whynot coal & 1337 & 1.34 & 0.55 & 35 & 2000 & 2600 & 0 \\
Shale & 2544 & 4.2 & 1.94 & 35 & 2000 & 1600 & 0 \\
Sandstone & 2550 & 3.7 & 2.7 & 40 & 4500 & 3200 & 0 \\
Overburden & 1800 & 0.3 & 0.2 & 22 & 50 & 10 & 3 \\
Dam wall and buttress & 2100 & 0.3 & 0.2 & 28 & 75 & 10 & 3 \\
\hline
\end{tabular}


Table 3 Properties of interfaces

\begin{tabular}{lcccccc}
\hline Interface & $\begin{array}{c}\text { Normal } \\
\text { Stiffness } \\
(\mathrm{GPa} / \mathrm{m})\end{array}$ & $\begin{array}{c}\text { Shear } \\
\text { Stiffness } \\
(\mathrm{GPa} / \mathrm{m})\end{array}$ & $\begin{array}{c}\text { Friction } \\
\text { Angle } \\
(\mathrm{deg})\end{array}$ & $\begin{array}{c}\text { Cohesion } \\
(\mathrm{MPa})\end{array}$ & $\begin{array}{c}\text { Tensile } \\
\text { Strength } \\
(\mathrm{MPa})\end{array}$ & $\begin{array}{c}\text { Dilation } \\
\text { Angle } \\
(\mathrm{deg})\end{array}$ \\
\hline $\begin{array}{l}\text { Floor of coal seams } \\
\begin{array}{l}\text { Interface between roof and floor } \\
\text { of excavated longwall }\end{array}\end{array}$ & 10 & 10 & 14 & 0 & 0 & 0 \\
\begin{tabular}{l} 
Dummy interfaces \\
\hline
\end{tabular} & 10 & 10 & 30 & 0 & 0 & 0 \\
\hline
\end{tabular}

\section{Subsidence modelling with FLAC ${ }^{3 \mathrm{D}}$}

\subsection{Capabilities of program FLAC ${ }^{3 D}$}

FLAC $^{3 \mathrm{D}}$ is a nonlinear stress analysis program that was developed primarily for use in geomechanics. It provides a wide range of elastic and nonlinear material constitutive models that can be used to describe the stress-strain response of geological materials, as well as interfaces to represent major discontinuities on which slip and/or separation may develop. The program can also treat nonlinear effects arising from large strains and deformations. In addition, a user can add extra features to the program, via the in-built programming language, FISH. This facility was used extensively in the analyses reported here.

The explicit finite difference method (FDM) for solving problems in nonlinear mechanics, which underlies FLAC $^{3 \mathrm{D}}$, is based on numerical time-stepping of the equations of motion for a discretised system representing the rock mass. This should be contrasted with most finite element and boundary element methods of stress analysis, which are based on equations of (assumed) equilibrium for the system. Because the FDM does not begin by assuming that the system is in equilibrium, it does not break down numerically if the system is loaded to a point where a failure begins to develop. This makes these programs very powerful for use in geomechanics, where dealing with potential failures is a necessary fact of engineering life. However, that advantage is balanced by the fact that the user must take greater care to adopt a modelling strategy that will produce physically realistic results. This includes setting up analyses with the program so that the numerical model is subjected to a stress path that reflects as closely as possible that for the real system, and ensuring that non-physical transient stress waves that are induced in the analysis when an excavation is created or extended do not cause physically inappropriate yield to occur anywhere within the model.

The most widely used nonlinear constitutive model in FLAC ${ }^{3 \mathrm{D}}$ is the Mohr-Coulomb model, where (isotropic) material strength is given by cohesion, friction angle and tensile strength. The model assumes non-associated plastic flow, unless a dilation angle is also specified. Unlike the corresponding model in other Itasca codes, the Mohr-Coulomb implementation in FLAC ${ }^{3 \mathrm{D}}$ does not reduce the tensile strength to zero in zones that have yielded in tension, i.e. it does not simulate the effect of tensile cracking. To simulate that effect (which is expected to play an important role in the development of subsidence in numerical models, and in reality), the strain-softening model must be used in FLAC ${ }^{3 \mathrm{D}}$. Only tensile softening has been treated (to zero tensile strength, almost immediately upon tensile yield), i.e. the shear strength of these rock units has been assumed to be unaffected by any yield in shear.

\subsection{Tests of modelling subsidence}

Early experience of modelling mining-induced subsidence (Coulthard and Dutton, 1988; Coulthard, 1992) had demonstrated that 2D continuum numerical models were not satisfactory and that discontinuum models would only predict realistic amounts of surface subsidence if they allowed for complex modes of deformation and failure, not only in the immediate roof strata, but also up through the overlying rock mass. When those models were first run, they took weeks of computer time to complete, so could only be pursued in a research environment. With subsequent advances in computer power, it is now quite feasible computationally to include this level of detail in 2D models for use in engineering design work. When 3D modelling of subsidence was required more recently (Coulthard, 2001), empirically-predicted subsidence patterns were applied as boundary conditions on the base of FLAC $^{3 \mathrm{D}}$ models, rather than attempting to 
simulate the development of subsidence within the model itself. Even now, 3D models akin to the earlier 2D models are not viable, but it was believed that the approach used by Coulthard (2001) could be improved upon. The tests that are summarised in the remainder of this section were designed to try to find such an improved approach to modelling mining-induced subsidence in 3D continuum analyses.

Many tests were run, initially as quasi-2D models, one layer of zones thick, with all out-of-plane displacements constrained, to simulate an infinitely long longwall panel, and then in full 3D. The latter included two longwalls, each $200 \mathrm{~m}$ wide, separated by a $50 \mathrm{~m}$ pillar. Zoning in these tests varied, but the final analyses all used zoning that was broadly equivalent to the zoning that was to be used in the inner region of the production models, so that any conclusions could validly be applied to those models.

The main results from the quasi-2D model tests were:

- When the full strengths of all the rock units were used (as in Table 2), failure of longwall roof strata occurred only in a small region above the excavation, and predicted maximum surface subsidence was small (around $0.2 \mathrm{~m}$ ) compared with observed values of 1.2-1.5 m (Todhunter, pers. comm.).

- If the cohesions and tensile strengths of all rock units, as used in earlier 2D models, were reduced by a factor of four or five, the predicted maximum surface subsidence was in the range $0.9-1.5 \mathrm{~m}$, with the shapes of subsidence curves across the longwalls also being broadly consistent with observations.

- If horizontal ubiquitous joints were added to the rock units, in a attempt to simulate the stated nature of the shale (laminated or fissile or both), the computed subsidence was increased. However the shape of the surface subsidence profile across a longwall panel no longer matched the observed shape; it was wider and flatter in the central region.

- Adding (horizontal) interfaces between layers at a couple of locations within the rock mass led to reduced surface subsidence, because separation on the interfaces tended to decouple the deformation of the strata on either side.

At that point, the development of an equivalent material (reduced strength) model showed considerable promise. However, when those reduced strengths were applied in 3D tests, the main results were:

- The computed surface subsidence varied along the length of the longwall panels, and reflected the excavation sequence that had been modelled. For example, extracting an $800 \mathrm{~m}$ long panel in four stages of $200 \mathrm{~m}$ produced quasi-elastic subsidence over the first stage of each panel, and maxima in the subsidence above the middle of each other stage of excavation. Those values were comparable with the maximum subsidence measured in the field (1.4-1.5 m), but computed subsidence reduced to about $1.1 \mathrm{~m}$ between those maxima (see upper plot in Figure 3).

- Excavation of the same longwalls in eight stages of $100 \mathrm{~m}$, which should produce a stress path that is closer to reality, resulted in only quasi-elastic subsidence at all surface points (around $0.2 \mathrm{~m}$ ).

- Inclusion of a crude simulation of the excavation of the tailings dam and open pit in these 3D tests had no qualitative effect on the computed subsidence, although maximum values at the surface (in the pit and dam floors) increased slightly.

The interim conclusion was that these 3D tests had failed to find a numerical solution strategy, and scaled rock properties, that produced subsidence over progressively-mined longwall panels that came plausibly close to matching the observed rock mass response. Given the sensitivity of the computed subsidence to the incremental mining procedure, and the fact that a real longwall face moves forward in increments that are very much smaller than the smallest $(100 \mathrm{~m})$ that had been used here, it was difficult to envisage a viable way forward. Analysis of the full system via sufficiently small longwall increments (i.e. such that the stress path, and so the development of rock mass yield and failure, would be reliable) would involve prohibitive amounts of computer time. In addition, the rock strengths would have to be reduced even further before reasonable subsidence would be computed even for $8 \times 100 \mathrm{~m}$ excavations of the longwalls.

In discussion, it was agreed that the only feasible way forward would be to accept that computational issues meant that any production models would have to be limited to extracting each longwall in four stages of $200 \mathrm{~m}$. The saved files were close to $400 \mathrm{MB}$ in size, and each excavation stage took about 2.5 hours to run, 
on our fastest computer at the time. In that case, the computed subsidence did match the observed values tolerably well. However, it must also be recognised that this limitation to longwall extraction being modelled in $200 \mathrm{~m}$ stages means that the models can only reflect the "global" response of the dam, pit walls and so on to mining-induced subsidence. It is not possible, for instance, to examine the details of the effects of the subsidence "wave" passing through the system, as the longwalls advance incrementally.

In addition, the zone sizes that had to be used, for the modelling to be feasible computationally, meant that other fine details, e.g. the possibility of a piping failure through the dam or its foundation, could not be assessed in these models.
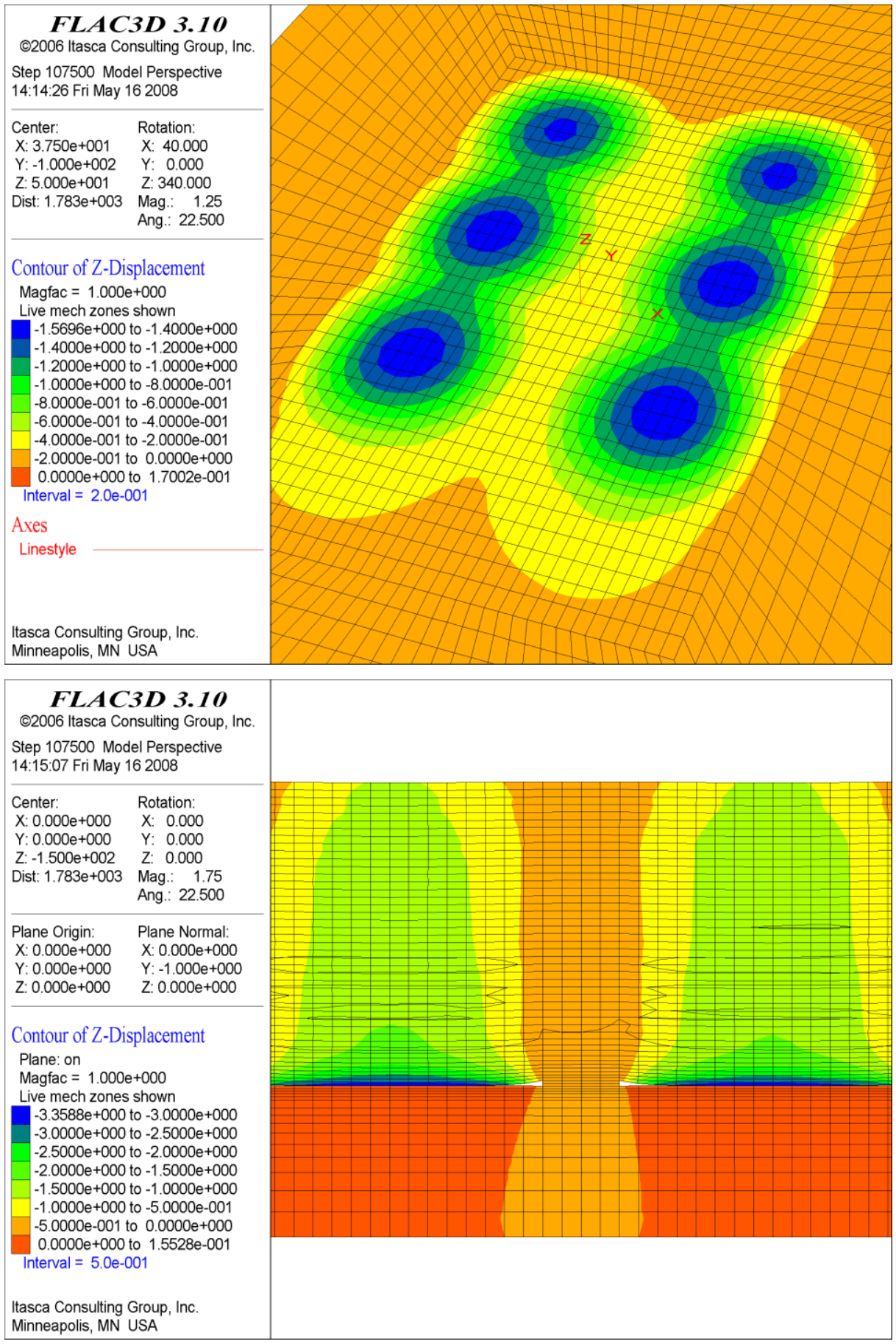

Figure 3 Computed subsidence in equivalent strength test analysis with four-stage excavation of each longwall panel: subsidence at surface (upper plot), subsidence on vertical section normal to longwall axes (lower plot) 
Within these constraints, it could be argued that the FLAC $^{3 \mathrm{D}}$ models provided a reasonable first approximation to the observed surface subsidence if the cohesion and tensile strength for each of the rock units was reduced by a factor of five from the values given in Table 2 . This is not to be taken as an adverse reflection on the accuracy of the values provided, but rather represents a sort of equivalent material model that makes up for, in a broad way, some of the inevitable limitations of the grid that must be used for these models. However, it should be emphasised that this is not a general-purpose equivalent material model for simulating subsidence, but has so far only been shown to be plausible for this specific grid and modelling strategy.

It should also be emphasised that assessment of this equivalent material form of model relied solely upon comparison between observed and computed surface subsidence. Had measurements also been available of sub-surface subsidence at this mine (Holla, 1987; Holla and Buizen, 1990), or of subsidence on pit floors, then a more thorough testing might have been possible.

\section{Global models of undermining of dam}

As previously discussed, the global model was to include:

- The same representation of the rock strata as used in the subsidence tests, with cohesions and tensile strengths of the rock units set to $20 \%$ of the values listed in Table 2 .

- Strata to dip at $2.5^{\circ}$ along direction of longwall panels (upwards from the region of Homestead pit towards the tailings dam).

- Lower strength interfaces at the base of the Wambo and Whynot seams, as in Table 3. The interface at the base of Wambo seam also underlies the overburden dump, and so will influence its mechanical response as well.

- Upper section of the grid rotated by $20^{\circ}$ relative to the direction of the longwall panels, to be consistent with the orientation of the proposed longwalls to the approximate long axes of the dam and pit.

- A simple representation of the dam, pit walls, buttress, etc., over the planned longwalls LW5 and LW6.

\subsection{Model geometry}

The basic structure of the global model is shown in Figure 4. The lower section extends up to the base of the Whynot seam, and contains the two longwall panels that are to be mined (beneath the finer-zoned central section). Each panel is $800 \mathrm{~m}$ long (in the direction of the global y-axis) and $200 \mathrm{~m}$ wide; there is a $50 \mathrm{~m}$ pillar between them. The outer vertical boundaries of the model were extended somewhat compared with those used for the subsidence tests, so that the closely-zoned inner section of the upper grid extended over most of the longwall panel region. The strata (and dip of those strata) in the model have already been shown in Figure 2. The uppermost coal layers (density $=1337$ ) in that plot represent respectively the Redbank, Wambo and Whynot seams. The second last coal layer is the Woodlands Hill seam (longwall mining).

The upper section was modified after the initial stress equilibration stage of the analysis, to include a simple representation of the tailings dam wall and buttress, overburden dump and Homestead pit (see cutaway views of those features in Figure 5). Note that there are some problems in that plot with the hidden line algorithm at the base of dam and buttress walls, but the actual zones were properly located on the underlying strata. The grid was set up to allow two possible configurations for Homestead pit, with $100 \mathrm{~m}$ difference in the distance from the pit to the tailings dam buttress. The tailings within the dam were not included explicitly, but were represented simply via pressure loads on the dam and overburden walls, and dam floor. 

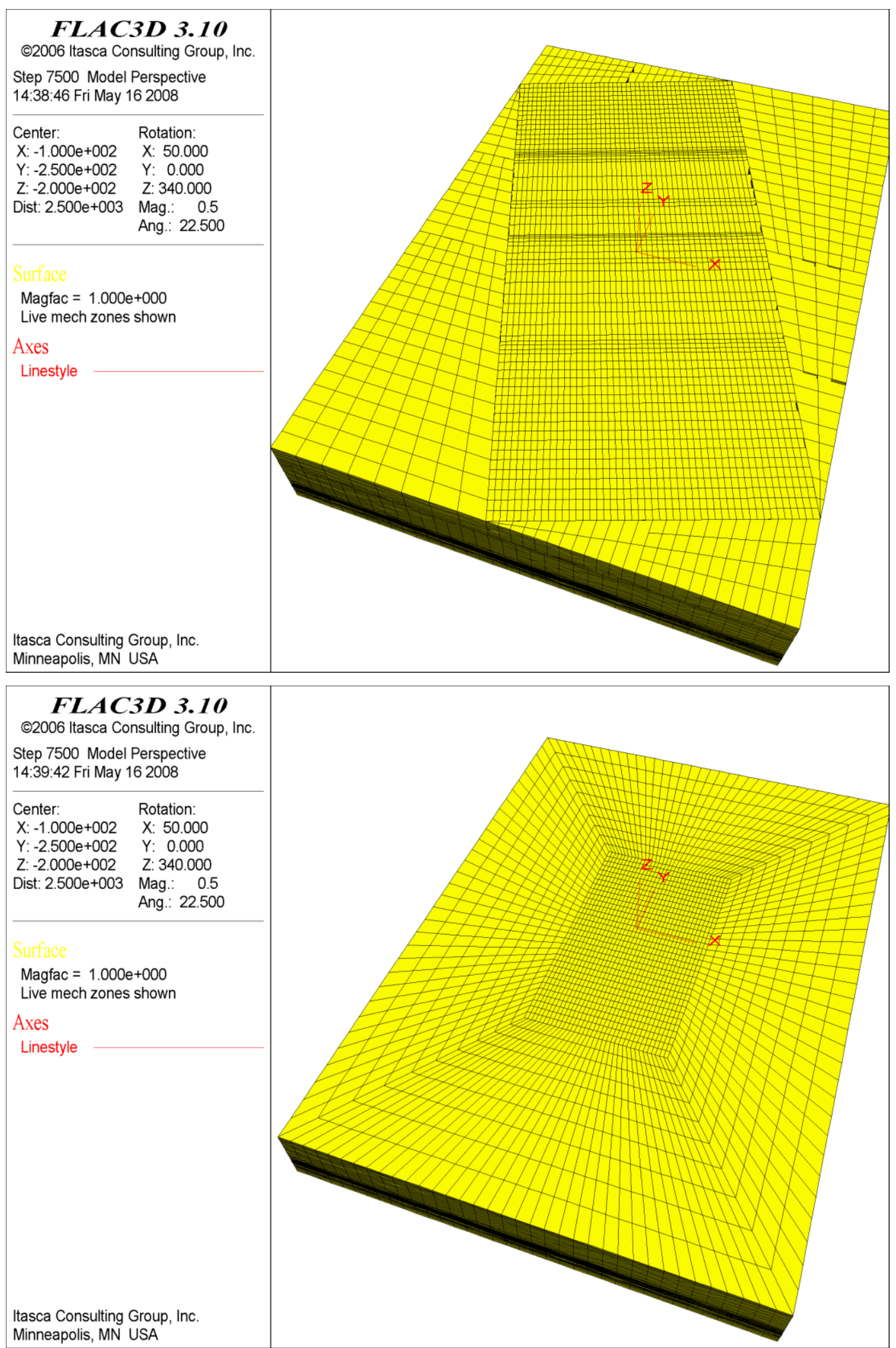

Figure 4 Structure of models of undermining of dam: upper part of model, in which open cut and dam will be created (upper plot); lower part of model, containing longwall panels (lower plot) 


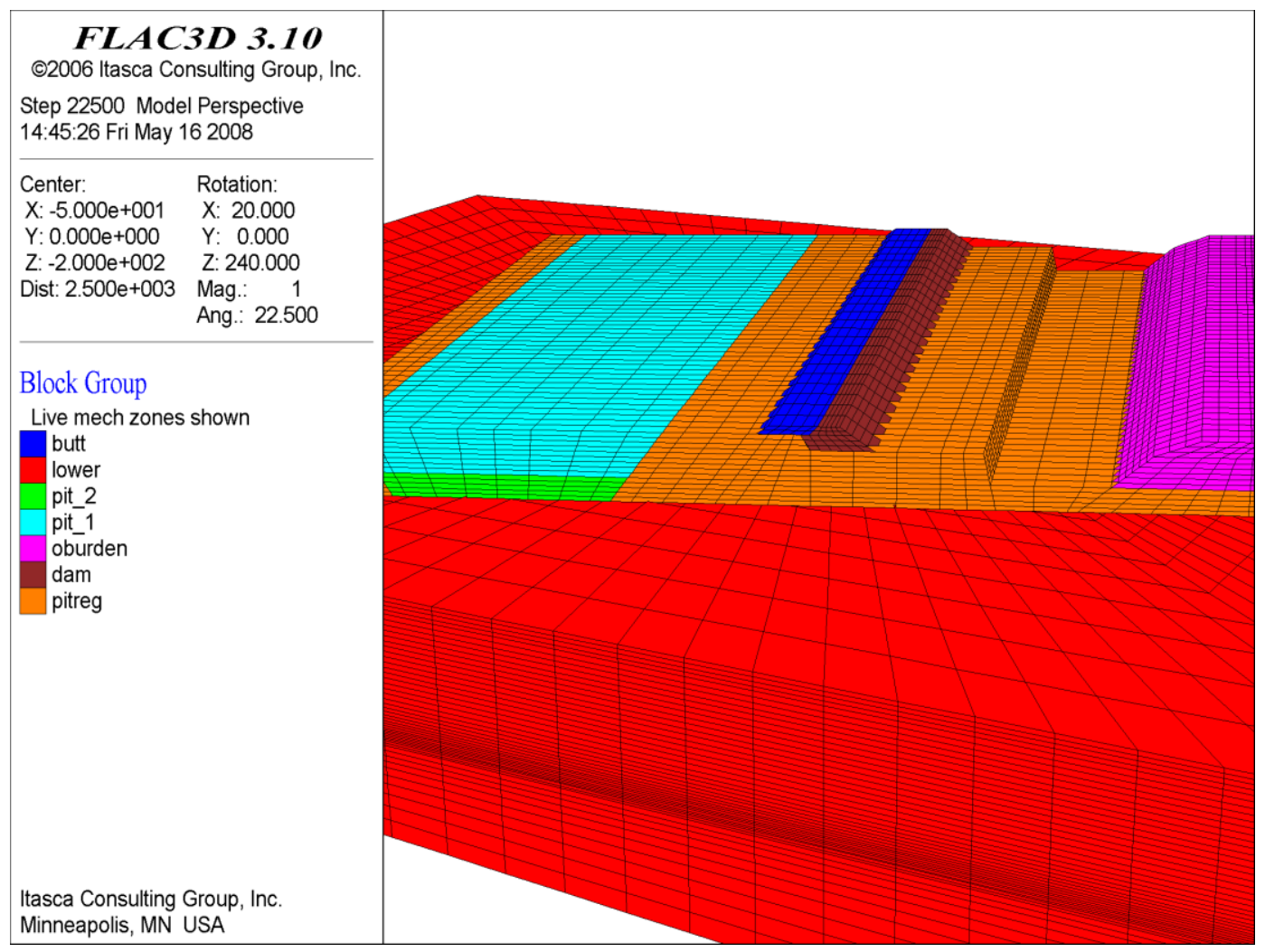

Figure 5 Cut-away view of representation of tailings dam, buttress and proposed open pit

\subsection{Modelling sequence}

The stages of modelling included in the initial global model were:

1. Equilibrate unmined system (with initial in situ horizontal stresses set via $\mathrm{K}_{0}=1.0$ ).

2. Excavate tailings dam, create dam wall, buttress and overburden dump.

3. Add pressure loads equivalent to placement of tailings in dam.

4. Excavate Homestead pit in two stages, to Wambo seam then to Whynot seam.

5. Mine longwall panels LW5 and LW6, each in four stages of $200 \mathrm{~m}$.

The results from each stage of the analysis were examined, to determine whether any failures were developing. These can be seen via plots of plastic state (which show regions of active shear or tensile yield, as well as those regions where yield has occurred in the past) and plots of velocity vectors or contours of velocity components. Starting from the final stage of an analysis, cohesions, tensile strengths and tangents of friction angles, for all rock materials and interfaces, were reduced by a strength reduction factor (SRF), then the computation was stepped further to observe how the system responded. If it remained stable, the SRF was progressively increased until a failure began to develop. The factor of safety (FoS) lies between the highest SRF value for which the system remains stable and the value at which a failure first develops. By continuing to increase the SRF, failures can be induced in different parts of a model, thus providing insight into the relative stability, and failure mechanisms, for those parts of the model.

\subsection{Summary of results}

A selection of the variants of the full global model that were run are summarised in Table 4 . The SRF values column shows the sequences of strength reduction factors that were run for each case. All of the dam and pit walls were predicted to be completely stable under the action of the induced stresses and strains that developed as they were undermined, in each of the global models. This was true even though the computed subsidence on the floor of Homestead pit (HP in Table 4) and the tailings dam were both significantly greater 
than the previously-computed (and observed) maximum surface subsidence of around $1.4 \mathrm{~m}$ (see Figure 6). The latter result is, of course, completely as expected, because the computed subsidence steadily increases from the surface towards the longwall panels, and the floors are necessarily closer to those seams. Other plots (not included here) show that nothing of significance occurred on the interfaces at this stage, when transient stresses had been dealt with carefully in the analysis for model glob_11a.

Table 4 Selection of variants of global model

\begin{tabular}{|c|c|c|c|}
\hline $\begin{array}{l}\text { Model } \\
\text { Name }\end{array}$ & Features & SRF Values & $\begin{array}{l}\text { Stability Analysis Results } \\
\text { (see note below) }\end{array}$ \\
\hline glob_10 & $\begin{array}{l}\text { Main model, as } \\
\text { discussed in text }\end{array}$ & $\begin{array}{l}1.0 \text { to } 2.0 \text { in steps } \\
\text { of } 0.2 \text {; } \\
1.80 \text { to } 1.95 \text { in } \\
\text { steps of } 0.05\end{array}$ & $\begin{array}{l}\text { All stable at } \mathrm{SRF}=1.85 \\
\text { Extensive failure in near wall of } \mathrm{HP} \text { at } \mathrm{SRF}=1.90 ; \\
\text { Small failure in near wall of tailings dam just } \\
\text { beginning at } \mathrm{SRF}=2.0\end{array}$ \\
\hline glob_10a & $\begin{array}{l}\text { Extend Homestead pit } \\
100 \text { m closer to } \\
\text { buttress/dam after } \\
\text { longwall mining }\end{array}$ & $\begin{array}{l}1.0 \text { to } 2.0 \text { in steps } \\
\text { of } 0.2 ; \\
1.80 \text { to } 1.90 ; 1.80 \\
\text { to } 1.85\end{array}$ & $\begin{array}{l}\text { Near wall of } \mathrm{HP} \text { just to equilibrium at } \mathrm{SRF}=1.80 \text {; } \\
\text { Extensive failure in near wall and side wall of } \mathrm{HP} \text { at } \\
\mathrm{SRF}=1.85 \text {; } \\
\text { Small failure in near wall of dam at } \mathrm{SRF}=2.0\end{array}$ \\
\hline glob_11 & $\begin{array}{l}\text { As for__ } 10, \text { but more } \\
\text { steps at each stage, so } \\
\text { closer to equilibrium }\end{array}$ & $\begin{array}{l}1.0 \text { to } 2.0 \text { in steps } \\
\text { of } 0.2\end{array}$ & $\begin{array}{l}\text { Essentially as for_10: all stable at } S R F=1.80 \text {; } \\
\text { failure in near wall of } \mathrm{HP} \text { at } \mathrm{SRF}=2.0\end{array}$ \\
\hline glob_11a & $\begin{array}{l}\text { As for_11, but with } \\
\text { quasi-elastic sub- } \\
\text { stages, to minimise } \\
\text { interface slip due to } \\
\text { non-physical transient } \\
\text { stresses }\end{array}$ & $\begin{array}{l}1.0 \text { to } 2.0 \text { in steps } \\
\text { of } 0.2\end{array}$ & $\begin{array}{l}\text { Reduced maximum shear displacement on } \\
\text { interfaces during LW mining; otherwise as for } \_11 \text {; } \\
\text { Stable at SRF }=1.80 \text {, development of failure at } \\
\text { SRF }=2.0 \text {, as for_11 }\end{array}$ \\
\hline
\end{tabular}

Note: "near" and "far" terminology for walls refers to distance from buttress and dam wall (as in Figure 5).

The stability of the various walls was then estimated by progressively reducing strength parameters for each of the rock units and interfaces, as outlined previously. FISH coding developed some years back by the first author was used to control the strength reduction. The 'solve fos' command in FLAC ${ }^{3 \mathrm{D}}$ has not yet been tried for this model, partly because it only produces a final, failing state. In contrast, our FISH code allows the interim stages to be checked for preliminary signs of failure, and also for the development of failures in separate parts of the slopes, at different SRF values, to be observed. It is noted that no assumption needs to be made about the form of any eventual failure, this develops naturally during this phase of the modelling, in response to the distributions of rock and interface strengths, and of induced stresses.

In all cases, the rock units were first converted from strain softening to Mohr-Coulomb material (in which strength parameters do not vary as a function of plastic strain), with the same strength parameters as existed in each zone at the end of longwall mining. That decision could be debated - a side effect is that further tensile cracking would not be developed as part of the SRF process. If tensile softening could be continued during the SRF computations, the computed FoS values would almost certainly be reduced, but it is not possible to estimate by how much without actually performing a revised analysis for one case. However, such a procedure would be contrary to the standard approach for assessing factors of safety.

In the glob_10 series, the first signs of any developing failure appeared in the "near" wall of Homestead pit (see footnote to Table 4), at a strength reduction factor (SRF) of 1.80, in each run with an extended Homestead pit. The case with the standard Homestead pit had been quite stable even at SRF $=1.85$. However, in each case that slope came to equilibrium after additional computational steps. An extensive failure of the slope developed clearly at $\mathrm{SRF}=1.85$ in both extended pit cases, and at SRF $=1.90$ for the standard pit. Such a failure might be expected to extend eventually through to the dam wall, particularly in the case of the extended pit, but this was not seen in any of these analyses. One side wall of the extended Homestead pit also failed at $\mathrm{SRF}=1.85$; this can be ignored as physically unrealistic because the necessarily 
crude representation of the pit in these models meant that that wall was set up as being vertical. Finally, a small failure just began to develop in a wall within the tailings dam at $\mathrm{SRF}=2.0$.

Extending Homestead pit $100 \mathrm{~m}$ towards the buttress and dam gave essentially the same results, whether this was modelled before or after longwall mining (in glob_10a and _10b respectively, Table 4). Similarly, simulation of auger mining in the tailings dam wall caused no significant changes in the predicted response to longwalling.

The computations for the final series of models were not extended to SRF values between 1.8 and 2.0. However, all showed very similar response otherwise: the various walls were still quite stable at SRF $=1.8$, but an extensive failure of the "near" wall of Homestead pit developed at SRF $=2.0$. The form of these various predicted failures is illustrated in Figure 7, which shows the failure as it had developed in model glob_11a. The failure mechanism that eventually developed involved slip on the interface at the base of the Whynot seam, as well as shear or tensile yield up through the rock strata to the surface, but falling short of the edge of the buttress. This is very similar in form to a simple sliding block failure but, as discussed above, it was not assumed in any way in this work. Rather, it arose naturally as part of the nonlinear stress analysis.

The implication of these analyses is that the factor of safety of the walls of the undermined Homestead pit, dam and so on is not less than 1.80, even for the case where Homestead pit is extended $100 \mathrm{~m}$ closer to the tailings dam. In the models based on the standard width for Homestead pit, the mechanism of failure that eventually developed was within the wall of the pit and did not extend to the buttress or dam.

\section{$5 \quad$ Engineering assessment}

In terms of open cut mining a factor of safety of 1.8 in the Singleton coal measures can be considered long term stable. Similarly, a factor of safety of 1.8 for an earth/rock embankment wall can be considered as indicating a stable embankment. The modelling thus suggested that undermining of the tailings dam embankment, and excavating an open cut to $20 \mathrm{~m}$ below the floor of the tailings dam, would not affect the stability of the embankment wall that partially surrounds the Northeast cut, nor affect the stability of the rock strata separating the tailings-filled Northeast cut from the Homestead pit. This assessment was supported by prior experience of United Collieries' longwall panels 2, 3 and 4 undermining the Northeast cut, adjacent open cuts and augered highwalls where there was no engineered embankment.

Since submission of the results of this modelling, and receipt of approval to extract the Woodlands Hill seam by the longwall method, longwall panels 5 and 6 were successfully extracted, with the mine moving on to longwall panel 7.

Subsidence and piezometer monitoring stations were installed on the embankment and at its toe to record deformations, and changes in groundwater. Maximum subsidence recorded over panel 5 was $1.25 \mathrm{~m}$ and over panel 6 was $1.37 \mathrm{~m}$ (Walker, 2008). The sandstone layers in the strata sequence reduced subsidence to values closer to those developed by the global models. No water movement through the wall was recorded in a series of piezometers located inside the embankment and at its toe. The piezometer locations are shown in Figure 1.

The Homestead pit continued operations, its only restriction at the present time being a standoff limitation of $150 \mathrm{~m}$ from the tailings dam embankment. Blasting vibration limits were eased from $20 \mathrm{~mm} / \mathrm{sec}^{2}$ to $50 \mathrm{~mm} / \mathrm{sec}^{2}$ as a result of blasting studies. 


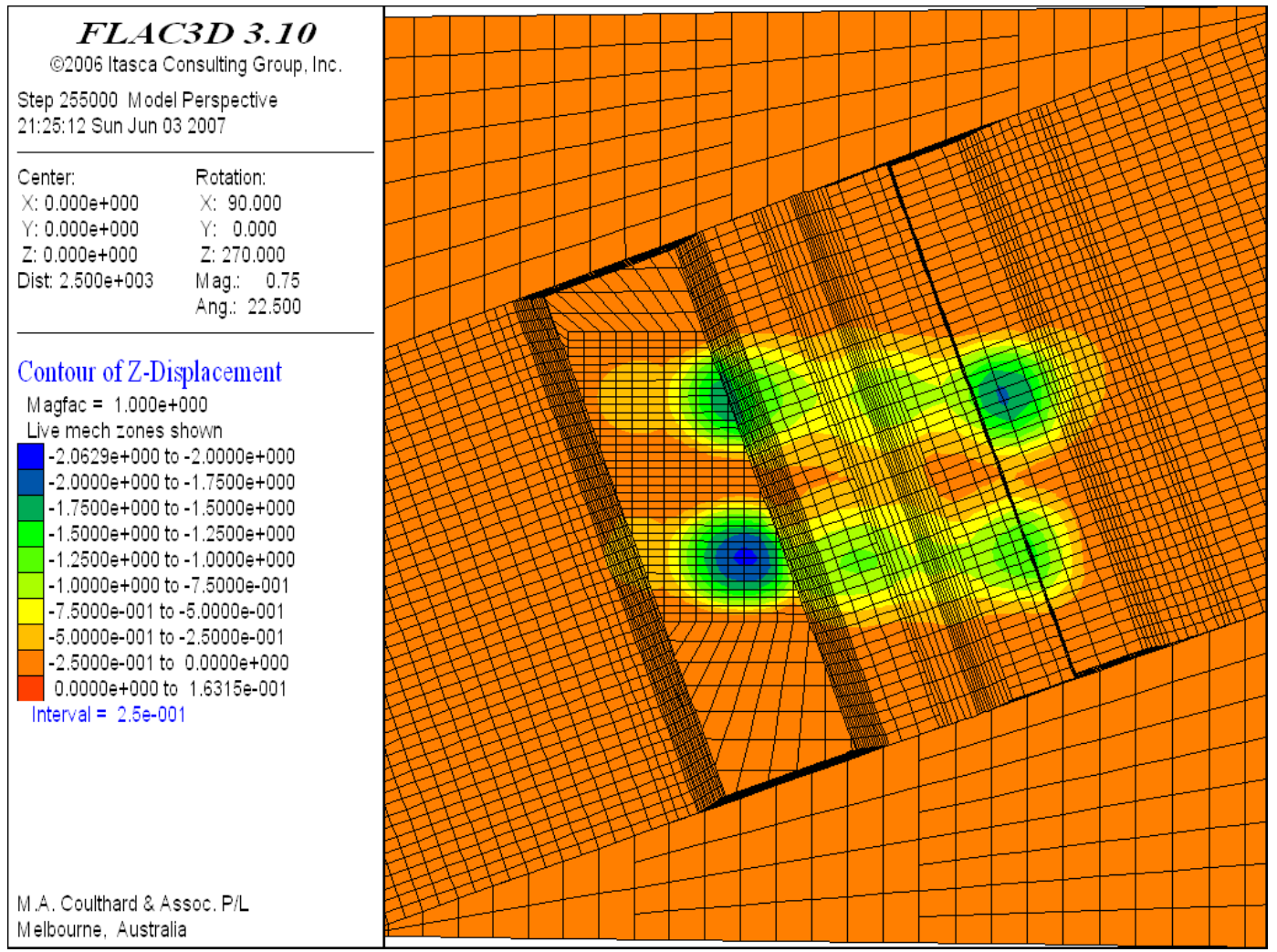

Figure 6 Surface subsidence, as computed in global model, before commencement of factor of safety analysis - predicted subsidence in floor of open cut now more than $\mathbf{2} \mathbf{m}$

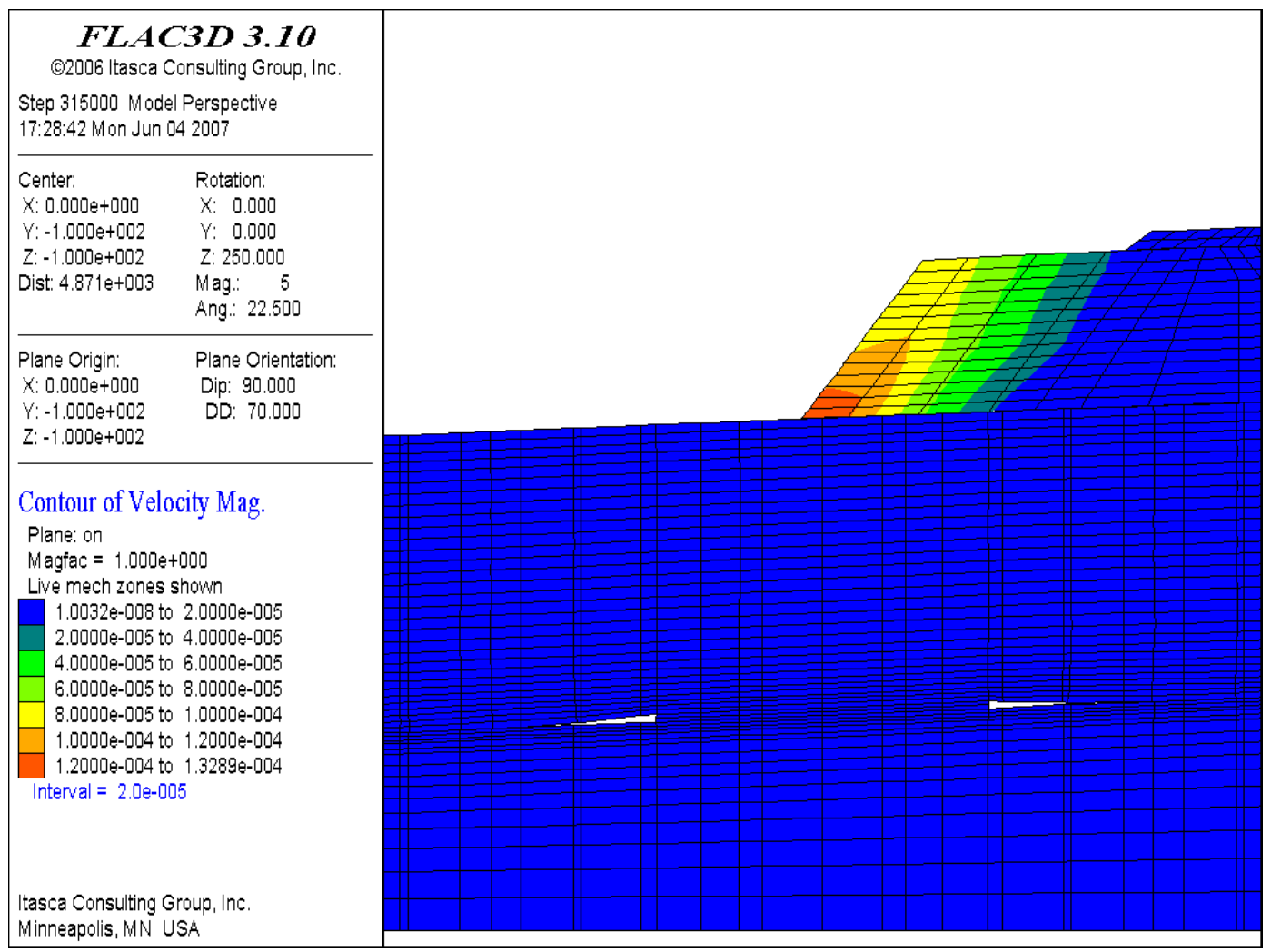

Figure 7 Failure developing in wall of Homestead pit at SRF = 2.0; partly closed longwalls beneath 


\section{Conclusions}

A simplified representation of the tailings dam wall and buttress, overburden dump and Homestead pit have been included in a FLAC ${ }^{3 \mathrm{D}}$ model, and the effects of undermining of this system have been investigated. In addition, the effects of extending Homestead pit $100 \mathrm{~m}$ closer to the tailings dam, and of previous auger mining of the Wambo seam in the wall of what is now the tailings dam, were examined in various versions of the global model.

All of the models predicted that all pit and dam walls would be stable at full strength, under the influence of stresses and strains induced by mining, where full strength actually means reduction by a factor of five of values previously used for cohesion and tensile strength of all rock units, so that the observed magnitudes of subsidence would be simulated. Progressive reduction of the strengths of rock material and interfaces from those values indicates that the various walls have a factor of safety of about 1.80 or better after being undermined by two longwall panels, LW5 and LW6. Extending the Homestead pit an additional $100 \mathrm{~m}$ towards the tailings dam made only a very small difference to the predicted factor of safety, reducing it by about 0.05 . The timing of the pit extension, before or after the longwall mining, was found to be of little consequence in these models. A simple simulation of prior auger mining in the wall of the tailings dam also showed no significant changes in the predicted response or factor of safety of the system.

Verification of the equivalent material model relied on matching as closely as possible actual surface subsidence measurements and knowledge of the pattern of ground movement above longwall panels. There was only anecdotal evidence that subsidence is greater at a pit floor than at the ground surface, so that aspect of the predictions of these models could not be checked. However, down-hole measurements of subsidence (Holla, 1987; Holla and Buizen, 1990) have indicated increased subsidence with distance from the surface. The reliability of these numerical models, and of the initial strength reduction procedure used to simulate subsidence magnitudes, might be further assessed if the predicted increased subsidence in the floor of the pit were to be found to be consistent with observed behaviour at the site.

\section{Acknowledgements}

The authors wish to acknowledge that United Collieries Pty Ltd and Wambo Coal Pty Ltd funded the initial study that is reported in this paper, and that they granted permission for this paper to be submitted.

\section{References}

Coulthard, M.A. and Dutton, A.J. (1988) Numerical Modelling of Subsidence Induced by Underground Coal Mining. Key Questions in Rock Mechanics, Proceedings 29th U.S. Symposium, P.A. Cundall, R.L. Sterling and A.M. Starfield (editors), pp. 529-536. Balkema, Rotterdam.

Coulthard, M.A. (1992) Distinct Element Modelling of Mining-induced Subsidence - a Case Study. Proceedings Conference on Fractured and Jointed Rock Masses, Lake Tahoe, L.R. Myer, C-F. Tsang, N.G.W. Cook and R.E. Goodman (editors), pp. 725-732, Balkema, Rotterdam.

Coulthard, M.A. (2001) Undermining of an Unlined Tunnel in Rock. FLAC and Numerical Modeling in Geomechanics, Lyon, France, D. Billaux, X. Rachez, C. Detournay and R. Hart (editors), pp. 265-272. Balkema, Rotterdam.

Holla, L. (1987) Design of Mine Workings Under Surface Waters in New South Wales, Proceedings AusIMM, Vol. 292, No. 2.

Holla, L. and Buizen, M. (1990) Strata Movement Due to Shallow Longwall Mining and the Effect on Ground Permeability, Proceedings AusIMM, Vol. 295, No 1.

Holt, G.E. (2003) Auger Stability Studies for Wambo and Whynot Seam Recovery, G.E. Holt and Assoc. Pty Ltd, report to Mining Operation Services Pty Ltd, March.

Itasca (2005) FLAC - Fast Lagrangian Analysis of Continua, version 5.0. Itasca Consulting Group, Inc., Minneapolis.

Itasca (2006) $F L A C^{3 D}$ - Fast Lagrangian Analysis of Continua in 3 Dimensions, version 3.1. Itasca Consulting Group, Inc., Minneapolis.

United Collieries Pty Ltd and Wambo Coal Pty Ltd (2006) The North East Cut Tailings Dam and Mining Impacts Dam Condition and Hazard Management report. United Collieries Pty Ltd and Wambo Coal Pty Ltd, Rev. 1.

Walker, M. (2008) Surface Subsidence Monitoring Data for Longwall Panels 5 and 6, United Colliery. United Collieries Pty Ltd, internal records. 